\title{
Internet use and Community Informatics in Brazil: speeding up or lagging behind?
}

\author{
Gilda Olinto \\ Instituto Brasileiro de Informação em Ciência e Tecnologia (IBICT); Programa de pós- \\ graduação em Ciência da Informação (PPGCI-IBICT/UFRJ)

\section{Suely Fragoso} \\ Universidade Federal do Rio Grande do Sul; Programa de pós-graduação em \\ Comunicação e Informação (PPGCom/UFRGS) and Programa de pós-graduação em \\ Design (PGDesign/UFRGS)
}

\begin{abstract}
The evolution of internet access and use in Brazil in the direction of social inclusiveness and to guarantee uses that promote individual and community development is the focus of the present paper. Previous evidence on the subject initially presented indicates the prevalence of contrasting aspects: some outstanding positive initiatives and results towards democratization of the internet, as well as the maintenance of great digital inequalities. New evidence on the evolution of internet access and use is also discussed herein, based on analyses of longitudinal data obtained from the Brazilian Census Bureau's Annual Survey (IBGE/PNAD, 2005, 2008). After describing aspects of increase in access to the internet, we focus on the evolution of different types of everyday life internet uses, particularly those that might contribute to individual and community development. How access and uses are gradually incorporating the less privileged sectors of the Brazilian adult population is also considered in the analysis. The results obtained reinforce the previous contrasting evidence: outstanding growth in access and in diversified uses are observed suggesting intensive appropriation of internet technology and resources by the population - as well as the persistence of great inequalities. These circumstances indicate that the digital divide in Brazil is still a great challenge to be faced through comprehensive and long-term policies and initiatives.
\end{abstract}

Keywords. Internet Access. Digital divide. Internet Use Survey. ICT in Brazil. Community development 


\section{Introduction}

Several difficulties characterized the initial phase of internet adoption in Brazil. After its late arrival in the 1980s, advances were slow due to diverse legal impediments and the state's telecommunications monopoly. However, the end of this monopoly, the creation of the first national backbones and TCP/IP and the advent of commercial access in the 1990s paved the way for accelerated internet growth in the country. E-government initiatives also developed quickly in the 1990s and deepened their scope at the federal, state and municipal levels after 2000 (Knight, 2007). E-voting in Brazil, for example, dates back to 1996 and online submission of the Annual Income Tax Declarations has been an option since 1997. The digital voting machine was the first ICT equipment used by many Brazilians and its dissemination has allowed for better integration of security systems, as well as acceleration of the vote counting process. A recent example of the efficiency of the Brazilian voting information technology was the official broadcast of the results of the 2010 presidential elections, involving almost 163 million voters, on the evening of Election Day!

The creation of the Brazilian Internet Steering Committee (CGI), a ministerial initiative aggregating governmental, private and academic institutions "in order to effectively promote the participation of Society in decisions regarding Internet implementation, management and usage"[1] in Brazil played an important part in the profile of internet use in Brazil. Amongst the chief responsibilities of the CGI are the management of the .br ccTLD[2]; attention to security problems regarding the Brazilian internet; collection and dissemination of data regarding internet development in Brazil; promotion of courses and events; and the development of projects to improve internet access in the country.

Nearly twenty years later, there is now widespread, even ubiquitous, internet presence in Brazil. The fast rate of adoption and the large number of users are probably the most visible of several peculiarities regarding the internet phenomenon in the country. Brazil shows outstanding numbers with respect to some specific features, such as hours of internet use, use of social network sites, site production, business use of the internet, as well as the total number or users. Governmental, NGO and private initiatives have also become widely known for their efforts of digital inclusion, especially those that seek to guarantee popular participation and content production.

The federal government continues to support several different and coordinated initiatives. The National Program of Support for Community Digital Inclusion (Telecentros.br)[3], controlled by three ministries (Communication, Science and Technology and Planning), for example, provides financial and logistic support for the creation of public internet access points and helps strengthen already existing public access sites. Another important initiative (initiated by then Minister of Culture the very well known Jazz musician/politician Gilberto Gil) is the Cultural Hotspot Program (Programa Pontos de Cultura)[4], promoted by the Ministry of Culture (MINC), which provides internet access, hardware and open source software for impoverished and historically excluded communities to create and share their own cultural and other materials (and of particular interest--music) on the internet. A third example of a program to which large resources are annually alloted is Casa Brasi[5] (Ministry of 
Science and Technology), whose aim is to finance specific projects that have been submitted to them.

The state of São Paulo, Brazil's richest and most populated state, has implemented a large network of public telecenters with the Programa Acessa SP[6]. Non-

Governmental Organizations and other private initiatives have also attained many positive results in the direction of digital inclusion of some significant sectors of the population. One example is the Committee for Democracy in Information Technology (CDI)[7], a non-governmental, non-profit organization. Since 1995, CDI has developed pioneer work in promoting social inclusion by using information technology as a tool for building active citizenship (Baggio, 2000).

These initiatives help to explain the outstanding Brazilian presence in the Internet and the fact that Brazilians with home access are already assiduous users. According to the Nielsen Netratings/lbope[8] partnership, at least since 2006, Brazilian users stay online longer than those from any other country. Most of their time online is spent on social network and communication sites leading to an outstanding presence on the web, which has been frequently reported, at least since the number of Brazilians surpassed the total of US users in Google's social network service Orkut in 2004 (Fragoso, 2006). Other similar services have also been heavily adopted in Brazil, such as Facebook, making Portuguese a widespread language on Twitter, MSN, YouTube and Blogs, for example.

Despite the positive aspects mentioned above, several negative features are also typical of internet development in Brazil, notably the social and technical underpinnings of internet access and use. Previous evidence shows that a great digital divide still prevails in the country. The socio-demographic characteristics of users - namely, education, income and race - are strongly related both to internet and broadband access and the types of uses that are made of the internet. Besides, as is the case in other developing countries, the less privileged portion of the population is the one that has access to the internet mostly in public, for profit sites (or cybercafes known in Brazil as "LAN houses") or from their homes, but with lower speed technology (CGI, 2009; IBGE, 2009). Likewise, internet access in schools, and its use for educational purposes, is still precarious (OECD, 2011; Sorj \& Lissovsky, 2011). Another negative aspect regarding digital inclusion projects is the lack of continuity and institutionalization of many projects that often have to rely on intermittent and uncertain public financing (Madon et al, 2007). The evolution towards an actual and effective democratization of internet access and use is an urgent issue that requires both intensification of programs and constant monitoring through data collection and analyses.

Considering the above-mentioned contrasting aspects of the internet phenomenon in Brazil, this article takes into account longitudinal evidence about the process of internet democratization in the country. The main focus is how internet access is actually growing and how the different types of internet use are evolving in the direction of citizenship and community building. 


\section{Types of internet use and characteristics of data}

There are many possible approaches when one tries to focus on the democratization perspective of internet access and use. These concepts - internet access and use can be seen from different points of view and answer different research questions; they can also be subjected to different measurements and analyses (Barzilai-Nahon et al., 2009).

The diversity of questions and perspectives about access and use is related to the constant changes characteristic of the internet, both in terms of access and technical features. They are all "moving targets that are difficult to aim at". Measures of internet use tend, therefore, to be only provisional and tenuous indicators of the concepts implied.

How these diverse, and constantly changing, uses of the internet tend towards inclusiveness and contribute to individual and group development is the challenge faced by several studies. Theoretical and empirical evidence on the subject suggests that this technology can, given favorable circumstances, bring about new opportunities for individuals and communities. However, an inverse process, one that perpetuates inequalities, is also possible with an implementation and use of the internet that "plugs into existing social structure" often maintaining or deepening inequalities in terms of access to culture (cultural capital), strategic contacts (social capital) and information for everyday life purposes that will, in turn, guarantee access to resources, such as better jobs (DiMaggio et al., 2004; Wellman et al., 2001; Wellman and Haythornthwaite, 2002). To take into account the characteristics of the social and cultural milieu of information technology in general, notably in developing countries, seems to have become a basic concern of information technology analysts and digital inclusion programs, notably of community and social informatics approaches (Gurstein, 2000, 2003; Williams \& Durrance, 2010).

This article tries to depict the evolution of internet access and the inclusive tendency of certain aspects of internet use in Brazil. The data presented here was obtained from the 2005 and the 2008 Annual Survey of the Brazilian Census Bureau (IBGE/PNAD, 2006; 2009). This survey includes a representative sample of the Brazilian population, comprising more than 400,000 interviews and, in both 2005 and 2008, the surveys included a special section on internet access and use. These studies provide a special opportunity to observe, from a longitudinal perspective, changes in access, including broadband access, and how the Brazilian adult population is in fact, incorporating different uses of the internet.

\section{Data analysis}

Considering the theoretical approaches of previous internet studies and the specificities of data utilized in the analyses, the first part of the empirical evidence presented herein focuses on access: its availability and technical characteristics, as well as its relation with the social-demographic characteristics of users. The second part of the analysis focuses on the evolution in types of internet use by Brazilian adults[9], especially of 
those uses that relate or contribute to individual and community development. The growth of such uses in the country and their tendency to become inclusive - in other words, how the relationship of these uses to the socio-demographic characteristics of users tends to diminish over time - are aspects considered in this work.

In Table 1, below, one can observe the evolution in numbers as well as the growth in the percentage of internet access in Brazil from 2005 to 2008 . The initial measure of access utilized here corresponds to a positive answer to the question "Have you used the internet from any place in the last three months?" The evolution of access at home, as well as of types of home access - dial up or broadband - is also shown in the same table.[10]

Table 1. Growth of Internet access by type of access. Brazilian adult population: 2005 - 2008.

\begin{tabular}{l|c|c|c}
\hline \multirow{2}{*}{ Type of Internet access } & \multicolumn{3}{|c}{ Internet access } \\
\cline { 2 - 4 } & 2005 & 2008 & \multirow{2}{*}{ N Growth } \\
\hline With Access & 24,127 & 40,450 & 67.6 \\
Access at home & 12,765 & 25,673 & 101.1 \\
At home With dial up & 7,447 & 4,748 & -36.2 \\
At home with Broadband & 6,178 & 20,926 & 238.7 \\
\hline
\end{tabular}

Source: IBGE (PNAD) Microdata. Adult population aged 18 years old or more in $2005(\mathrm{~N}=132,708)$ and in 2008 ( $N=124,425$ million).

As indicated in table 1, ten years after the beginning of commercial availability of the internet in Brazil, the absolute numbers of access has reached impressive figures and growth of internet access in the three year period between these surveys is remarkable: it goes from just over 24 million to well above 40 million of adults with access, a growth rate of almost $70 \%$, an outstanding figure if compared to those observed in other countries (Fox, 2005; Horrigan, 2008). The measure of home access has also shown a particularly important increase during the time studied: a growth rate of above $100 \%$. And if one focuses on home access through broadband, the increase is even more impressive, a growth rate of nearly $240 \%$ testifying to the effective dissemination of this type of internet home access. A vertiginous decline of dial up access in the period is also evident suggesting that a very rapid technological substitution took place in the period.

It is important to consider, however, the negative aspects that can also be depicted from Table 1. In the first place, the extremely tenuous measure of "internet access" having had access in the last three months - begs the question: is it sufficient to characterize digital inclusion? Apart from that, the number of over 40 million with this access should be considered still very low if compared with the adult population of Brazil in 2008 (133 million). Thus, only $32.5 \%$ of Brazilian adults indicate having had internet access in 2008. Besides, the large number of respondents who indicated having had some kind of internet access did not have a home connection. In other words, of the 40 million adults that are considered as having access in 2008 , only some 25 million can access internet in their homes. This scenario confirms previous 
diagnoses of the importance of public paid internet sites (LAN houses), in Brazil and other Latin American Nations, particularly for the low income population. These characteristics have implications for digital inclusion public policies, especially the attention that should be given to private initiatives as well as to the increase in free-ofcharge access point in public institutions such as public telecenters and public libraries (IBGE, 2009; CGI, 2009; Fragoso \& Maldonado, 2010; Gomez \& Baron-Porras, 2010 ; Olinto, 2010).

The observed increase in the number of adults who access the internet, as shown above, does not indicate who is being digitally included. To verify how much increase in access is socially inclusive, benefiting all sectors of the population and tending to absorb the less privileged, the following table describes access changes by sociodemographic characteristics of users.

Table 2. Growth of internet access by socio-demographic profile of population. Brazilian adult population: 2005- 2008.

\begin{tabular}{|c|c|c|c|}
\hline $\begin{array}{l}\text { Socio-demographic } \\
\text { characteristic }\end{array}$ & $\begin{array}{r}\text { N (Million) } \\
2005\end{array}$ & $\begin{array}{c}\text { N (Million) } \\
2008\end{array}$ & $\%$ Growth \\
\hline \multicolumn{4}{|l|}{ Age } \\
\hline $18-29$ & 11,843 & 19,834 & 67.5 \\
\hline $30-49$ & 9,769 & 16,168 & 65.5 \\
\hline $50-64$ & 2,260 & 3,893 & 72.3 \\
\hline $65 \mathrm{e}+$ & 0,254 & 0,555 & 118.5 \\
\hline \multicolumn{4}{|l|}{ Gender } \\
\hline Male & 12,270 & 20,021 & 63.2 \\
\hline Female & 11,857 & 20,429 & 72.3 \\
\hline \multicolumn{4}{|l|}{ Race } \\
\hline White & 16,699 & 24,869 & 48.9 \\
\hline Afro-Brazilian & 7,092 & 15,098 & 112.9 \\
\hline Other & 0,336 & 0,483 & 43.8 \\
\hline \multicolumn{4}{|l|}{ Years of Education } \\
\hline 10 or less & 3,731 & 8,691 & 132.9 \\
\hline 11 to 14 & 13,893 & 22,742 & 63.7 \\
\hline 15 or more & 6,476 & 8,966 & 38.4 \\
\hline \multicolumn{4}{|c|}{ Minimum family income ${ }^{[12]}$} \\
\hline 2 or less & 13,507 & 22,239 & 64.6 \\
\hline More than 2 to 5 & 6,934 & 11,381 & 64.1 \\
\hline More than 5 to 10 & 2,129 & 3,579 & 68.1 \\
\hline More than 10 & 0,770 & 1,406 & 82.6 \\
\hline
\end{tabular}

Source: IBGE (PNAD, 2005 and 2008) Microdata. Population aged 18 years old or more.

Observation of changes of internet access in terms of the social profile of users (Table 2) indicates that growth in this three years period was high in all segments considered and, of particular interest, beneficial to those who usually lag behind in the process: it has favored older people, women, Afro-Brazilians and those at lower level of the educational ladder. Although the increase in internet access in the period studied was largest among the highest income group, it appears to have been particularly beneficial for those in lowest income strata, especially considering the high numbers 
involved: internet access in this income group jumped from 13 million in 2005 to 22 million in 2008. These inclusive characteristics of access to the internet, as suggested in Table 2, are likely to be related, at least partially, to the comprehensive public policies previously mentioned.

The favorable tendencies noted above should not turn our attention away from observing that internet access in Brazil is still very low in terms of the Brazilian population as a whole and in comparison with developed countries. As an example, in 2005, some $68 \%$ of American adults had access to the internet as compared to only $19 \%$ of Brazilian adults (Olinto, 2008). Furthermore, socioeconomic factors seem to have a strong influence on access and use of the internet in Brazil. The social stratification of internet access and use is presented in Table 3, below, which considers the relationship between education and income level of users and two aspects of internet access and use: a general measure of access and availability at home through the more advanced technology--broadband-- in the year of 2008.

Table 3. Internet access and broadband use by education and income. Brazilian adult population in 2008.

\begin{tabular}{l|c|c}
\hline $\begin{array}{l}\text { Socio-economic } \\
\text { characteristic }\end{array}$ & $\begin{array}{c}\text { \% of access } \\
\text { in population }\end{array}$ & $\begin{array}{c}\text { \% of users } \\
\text { with home } \\
\text { broadband access }\end{array}$ \\
\hline $\begin{array}{l}\text { By Years of Education } \\
10 \text { or less }\end{array}$ & 10.6 & \\
11 to 14 & 57.7 & 35.6 \\
15 or more & 81.0 & 49.0 \\
& & 74.5 \\
By minimum family income $[12]$ & & \\
2 or less & 28.2 & 35.6 \\
More than 2 to 5 & 55.9 & 66.5 \\
$\quad$ More than 5 to 10 & 72.5 & 83.6 \\
More than 10 & 76.6 & 88.1 \\
\hline
\end{tabular}

Source: IBGE (PNAD, 2008) Microdata. Population aged 18 years old or more.

From the above table it can be seen that internet access strongly increases as the years of formal education and income level of users grow. As well the same relationship holds for those with broadband access in the home. These socio-technical underpinnings of internet access have been found in developed countries, but the differences are not so sharp (Horrigan, 2008). The fact that only $10 \%$ of adults in the lower educational group had internet access in 2008 points to the urgency of strong measures of digital inclusion, as this segment is the largest in absolute numbers, comprising almost 82 million or above $65 \%$ of the adult population of Brazil (IBGE/PNAD, 2009).

The focus of the analysis turns now to purposes of internet use, as measured in the two Bureau of Census surveys. The selection and grouping of these purposes gives emphasis to everyday life uses that might contribute to aspects of individual or community development and citizenship. 
The four categories of uses are: 1) those uses that could be considered as contributing to or being directly related to the acquisition of cultural capital (DiMaggio, 1982), such as distance learning, reading the news, etc.; 2) those that contribute or are more directly related to the acquisition of social capital (Nan Lin, 2001; Wellman et al, 2002), for example the use of email, instant messaging, blogs, social network systems, etc.; 3) instrumental uses that are linked to the use of the internet for the solution of everyday life problems, such as access to government resources, health-related services, shopping and banking (Savolainen, 1999; Eastabrook, 2007; Wellman and Heythornthwaite, 2002); and 4) entertainment activities, such as those involving music, videos, games, etc, are also considered here, due to the absolute numbers involved and due to the possible contribution of these activities to digital inclusion, especially of the less privileged segments of the population (Fragoso et al, 2011). It is important to emphasize here that these four categories of uses should not be understood as mutually exclusive or independent of each other. For example, activities that enhance social capital, such as online communication, are an important part of distance learning and/or or news sharing. At the same time, it is easy to see online communication as a form of entertainment.

Table 4, as follows, examines the evolution of these types of internet use purposes from 2005 to 2008 in Brazil.

Table 4. Growth of types of internet uses.

Brazilian adult users: 2005 - 2008 (in Millions).

\begin{tabular}{l|c|c|c}
\hline Internet Uses & 2005 & 2008 & $\%$ Growth \\
\hline Contributing to Cultural capital & & & \\
$\quad$ Educational activities & 15,909 & 24,445 & 53.7 \\
$\quad$ Reading the news & 12,586 & 22,881 & 81.8 \\
Contributing to Social Capital & & & \\
Communication & 16,807 & 33,428 & 98.9 \\
Instrumental Uses & & & \\
$\quad$ Accessing Government & 8,493 & 8,209 & -3.3 \\
Searching for info \& services & 7,109 & 12,752 & 79.4 \\
Shopping & 4,189 & 8,296 & 98.0 \\
Banking & 6,004 & 7,258 & 20.9 \\
Entertainment & & & \\
Music, Videos, Games & 11,824 & 25,829 & 118.5 \\
\hline
\end{tabular}

Source: IBGE (PNAD, 2005, 2008) Microdata. Population aged 18 years old or more.

The analysis presented in Table 4 reveals significant growth in most of the uses considered, and the growth pattern is similar to the one observed in the previous analyses focusing on internet access. The use of the net for communication - e-mails, chats, social network sites, blogs and fotologs - involves the largest absolute number of people and is also the type of use that shows the greatest gains in the period 
(98.9\%). This reinforces previously mentioned evidence that links the heavy use of social network sites to long hours of internet use in Brazil, indicating that Brazilians seem to invest a great deal in their social capital. Activities that were considered as contributing to cultural capital acquisition also increased significantly in the period and involve a significant portion of those who have access to the internet. The increase in online news reading is outstanding ( $81.8 \%)$, indicating the importance of the internet for the future of journalism in Brazil.

Although some of the other types of internet use defined here as instrumental - those that aim at the solution of everyday life needs - show significant growth in the period (such as searching for information and services and shopping), it is clear that they are a niche activity that concern a very small portion of adult internet users. Surprisingly, using the internet to access government or public authorities (for obtaining documents, sending income tax returns, or scheduling medical appointments) not only involved a very small portion of the population but also declined in the period.

Using the internet for banking was also adopted by only a small proportion of Brazilians, showing only a small increase in the period. This is further evidence of the contrasting aspects of the internet in a country which is known for technologically advanced and widespread ICT use for banking activities and, at the same time, for the low percentage of its population with bank accounts.

This low instrumental use of the net is counterpointed by the amazing involvement of Brazilian adults with entertainment activities, which includes watching, listening and downloading TV programs, music, videos and games; activities that have had the largest growth in the period. These results contribute to the idea that leisure should be taken seriously as a subject, at least by researchers and educators.

Table 5, presents evidence of the importance of the social characteristics of the internet user in relation to types of internet use through the relationship between the educational level of the user-corresponding roughly with elementary, secondary and college educational level of the user - with the different types of internet uses that he or she makes of the internet. 
Table 5. Internet uses by years of education. Brazilian adult users, 2008.

\begin{tabular}{l|c|c|c}
\hline \multirow{2}{*}{ Internet Uses } & \multicolumn{3}{|c}{ Years of Education } \\
\cline { 2 - 4 } & $\begin{array}{c}10 \text { or less } \\
\%\end{array}$ & $\begin{array}{c}11 \text { to } 14 \\
\%\end{array}$ & $\begin{array}{c}15 \text { or more } \\
\%\end{array}$ \\
\hline $\begin{array}{l}\text { Contributing to Cultural capital } \\
\text { Educational activities }\end{array}$ & 46.2 & 60.8 & 73.3 \\
$\quad$ Reading the news & 41.0 & 57.2 & 70.2 \\
Contributing to Social Capital & & & \\
$\quad$ Communication & 78.1 & 83.1 & 85.8 \\
Instrumental Uses & & & \\
$\quad$ Accessing Government & 8.7 & 18.2 & 37.0 \\
$\quad$ Searching for info. and services & 23.0 & 34.0 & 33.6 \\
$\quad$ Shopping & 8.7 & 18.5 & 37.1 \\
$\quad$ Banking & 6.5 & 15.4 & 35.5 \\
Entertainment & & & \\
$\quad$ Music, Videos, Games & 62.6 & 65.8 & 60.3 \\
TOTAL (Millions) & 8,691 & 22,742 & 8,966 \\
\hline
\end{tabular}

Source: IBGE (PNAD, 2008) Microdata. Population aged 18 years old or more.

By interpreting the numbers from Table 5, one can see that certain uses of the net, as measured here, tend to "universality" in the sense that they involve large numbers and will soon probably be guaranteed to all, independently of the social origin of the user. This is the case of internet use for communication which, besides involving a very large number of users, in all three educational levels, also indicates only a slight relationship with the user's educational level. Some other uses, also involving large numbers of users, could be called relatively "democratic" in the sense that, although not tending to involve all internet users, they do not seem to be affected by the educational level of the users. This is especially the case in the use of the net for entertainment purposes. However, several instrumental uses - banking, shopping and accessing the government - as well as the activities relating to the acquisition of cultural capital education and reading the news - indicate a clear correlation with the educational background of users. This suggests that theoretical questions about social inequalities being brought to the virtual world are still valid and strong.

On the whole, data analyses regarding changes in the types of internet use in Brazil from 2005 to 2008 reveal a general tendency towards growth, accompanying the increase in internet access. Communication activities - an important element of an individual's social capital and a basic ingredient for the vitality of contemporary communities - are almost universal among those who have internet access. However, some basic instrumental uses of the internet involving the solution of everyday life needs, such as searching for information and services, or citizenship building activities, such as the ability to access the government, show restricted use by the population at large and remain largely restricted to those with higher levels of education. 


\section{Concluding remarks}

As the title of this paper suggests, several apparent paradoxes make it hard to diagnose Brazil's present conditions with respect to ICTs, particularly internet access and use. Are we speeding up, and going in the right direction, or are we lagging dangerously behind and establishing even larger social gaps with ICTs instead of bridging existing ones?

Initial evidence presented indicates that the increase in the total number of users and of a diverse range of uses of the net is impressive enough to place the country amongst the leading positions in some internet rankings. The spontaneous appropriation of internet resources, notably social network systems, is remarkable. Several programs aiming at digital inclusion and universal access to ICT, mobilization of a wide range of different actors in both governmental and private sectors, as well as a concerted action of public agencies are characteristics of the Brazilian initiatives that seem to be promoting internet access and, to a certain extent, an effective socio-digital inclusion.

The analysis of the evolution of the internet in the three-year period between 2005 and 2008 also indicates a number of positive and impressive results. With respect to access, the general increase is outstanding, as well as the growth of broadband home access, notably by the less privileged sector of the population. Internet uses that are often associated with the increase of individual life chances and citizenship development also show a significant increase, as is the case of internet use for communication, newspaper reading and educational purposes.

In contrast to these improvements, some negative aspects also stand out. As the analyses presented here helped to reveal, the proportion of the adult population with internet access, especially with home access, is still very low. Social differences in access and use are pronounced and the use of digital resources for some everyday life activities by citizens is as yet undeveloped. Access and growth of internet use for some public or private services, such as e-banking, is a privilege that benefits only very few Brazilians. Further initiatives towards digital inclusion in Brazil should recognized that the digital divide remains an enormous and complex challenge, requiring wellstructured, long-lasting and comprehensive policies to be properly addressed.

\section{Acknowledgement}

We are grateful to CNPq (Conselho Nacional de Desenvolvimento Científico e Tecnológico) for financial support. We are also grateful to Ennio Leite de Mello of IBGE for his valuable contribution.

\section{References}

Barzilai-Nahon K.; Gomez, R. \& Ambikar, R. (2009). Conceptualizing Contextual Measurements for Digital Divide/s: Using an Integrative Narrative. In: Ferro E., Dwivedi Y.K., Ramon G, Williams M.D (Eds). Overcoming Digital Divides: Constructing an Equitable and Competitive Information Society, (Eds.), Idea Group Inc.

Baggio, R. (2000). A sociedade da informação e a infoexclusão. Ciência da Informação, 29 (2), 16-21. 
Carvalho, M. S. R. M. (2006). A trajetória da Internet no Brasil: do surgimento das redes de computadores à instituição dos mecanismos de governança. M.Sc. thesis presented to UFRJ/Engineering.

Castells, M.A. (2003). A galáxia da Internet: reflexoes sobre a Internet, os Negócios e a Sociedade. Rio de Janeiro: Zahar.

CGI - Comitê Gestor da Internet no Brasil (2009). Pesquisa sobre uso das tecnologias de informação e comunicaçao no Brasil. http://www.cetic.br/tic/2006/indicadores2009.pdf

Chen, W. \& Wellman, B. (2004). The global digital divide-within and between countries. IT\& Society, 1 (7), 39-45. http://www.ITandSociety.org

DiMaggio, P., Hargittai, E., Celeste, C. \& Shafer, S. (2004) From unequal access to differentiated use: a literature review and agenda for search on digital inequality. In: K. Neckerman (Ed.) Social Inequality. New York: Russell Sage.

DiMaggio, P. (1982) Cultural capital and school success: the impact of status culture participation on the grades of U.S. high school students. American Sociological Review, 47(April), 2002, 189-201.

Eastabrook, L. (2007) Information searches that solve problems. Washington: Pew Internet American Life Project. http://www.pewinternet.org/

Fragoso, S. (2006). WTF a Crazy Brazilian Invasion. In F. Sudweeks \& H. Hrachovec (Eds.), Proceedings of CATaC 2006, pp. 255-274. Murdoch, Australia: Murdoch University.

Fragoso, S. ; Maldonado, A. E. (2010). The Internet in Latin America. In: Hunsinger,J. et al. (Org). International Handbook of Internet Research. New York: Springer, v. 1, p. 164-180.

Fragoso, S. ; Cogo, D; Brignol, L.D. (2011). What does it mean, to bridge the divide? Learning from spontaneous practices towards ICTs. In: STEYN, J.; Johanson, G. (Org.). ICTs and Sustainable Solutions for the Digital Divide: Theory and Perspectives. Hershey: IGI Global. v. 1, p. 151-170.

Fox, S. (2005) Digital Divisions. Washington: Pew Internet American Life Project. 12p. http://www.pewinternet.org/

Gomez, R.; Baron-Porras, LF. (2010) Public Access to the Internet and Social Change: An experience in Colombia, between silence and hope. Community Informatics, 6 (3). http://www.ci-journal.net/index.php/ciej/article/view/724

Gurstein, M. (2003). Effective use: a community informatics strategy beyond the Digital Divide. First Monday, 8 (12). http://www.firstmonday.org/issues/issue8_12/gurstein/

Gurstein, M. (2000). Community Informatics: Enabling Communities with Information and Communications Technologies. Idea Group. 
Horrigan, J.B. (2008). Home broadband adoption-2008. Washington: Pew Internet American Life Project. 12p. http://www.pewinternet.org/

IBGE/PNAD (Instituto Brasileiro de Geografia e Estatistica - Pesquisa Nacional por Amostra de Domicílios-2005) (2006). Acesso à Internet e posse de telefone móvel celular para uso pessoal. Rio de Janeiro: IBGE.

http://www.ibge.gov.br/home/estatistica/populacao/acessoalnternet/Internet.pdf

IBGE/PNAD (Instituto Brasileiro de Geografia e Estatistica - Pesquisa Nacional por Amostra de Domicílios-2008) (2009). Síntese dos indicadores. Rio de Janeiro: IBGE. http://www.ibge.gov.br/home/estatistica/populacao/trabalhorendimento/pnad2009/sinte sepnad2009.pdf

Knight, P.E. (2007). Knowledge Management and e-Government in Brazil. Workshop on Managing Knowledge to Build Trust in Government 7th Global Forum on Reinventing Government, 26-29, June 2007, Vienna, Austria.

Madon, S.; Reinhard, N.; Roode, D.; Wlasham, G. (2007). Digital inclusion projects in developing countries: process of institutionalization. In: $9^{\text {th }}$ International Conference on Social Implications of Computers in developing countries, São Paulo, Brazil.

Proceedings.

Lin, N. (2001). Social Capital: A Theory of Social Structure and Action. Cambridge: Cambridge University Press.

OECD (2011). Organization for Economic Coorperation and Development. Pisa 2009 Results: What makes a school successful. www.oecd.org/edu/pisa/2009

Olinto, G. (2008). Everyday Life Internet Use in Brazil. In: Internet Research 9.0: Rethinking Community, Rethinking Place, 2008, Copenhagen. Internet Research 9.0.

Olinto, G. (2010). Internet access and use in Brazil: concepts, measures, and public libraries as social facilitators. In: Katsirikou, A; Skiadas, C.H.. (Org.). Qualitative and Quantitative Methods in Libraries: Theory and Applications. Londres: World Scientific Publishing.

Olinto, G. (2010). Bibliotecas públicas e uso das tecnologias de informação e comunicação para o desenvolvimento social. InCIC: Revista de Ciência da Informação e Documentação, 1(1), 77-93.

Robinson, J., Di Maggio, P., Hargittai, E. (2003). New social survey perspectives on the digital divide. IT\& Society, 1(5), 1-22. http://www.ITandSociety.org

Sorj, B.; Lissovsky, M. (2011) Internet nas escolas públicas: políticas além da política. Centro Edelstein de Pesquisas Sociais. Working Paper n.6, March.

www.centroedelstein,org.br

Wellman, B. et al. (2001). Does the internet increase, decrease or supplement social capital? Social netwoks, participation, and community commitment". American

Behavioral Scientist, 45 (3), 437-456. 
Wellman, B. \& Waythornthwaite, C. (Eds.) (2002). The Internet in Everyday Life. Oxford: Blackwell.

Williams, K.; Durrance, J. C. (2010). Community Informatics. In: Bates, M. J. et al (Eds.) Encyclopedia of Library and Information Sciences. New York: Taylor \& Francis, 1202-1208.

[1] Comitê gestor da Internet, HTTP://wwwcgi.br

[2] ccTLD stands for Country Code Top Level Domains that, in principle, identify a particular country or geographical territory (for example .br, .ca, .ar, etc.)

[3] http://www.telecentros.br.com/

[4] Cultural Hotspot Programme (Programa Pontos de Cultura) is one of the actions of the Live Culture Programme. Details can be found at http://www.cultura.gov.br/culturaviva/

[5] http://www.casabrasil.gov.br/

[6] http://www.acessasaopaulo.sp.gov.br/

[7] http://www.cdi.org.br

[8]http://www.ibope.com.br/calandraWeb/servlet/CalandraRedirect?temp=5\&proj= IBOPEenglish\&pub=T\&comp=IBOPE+Group\&db=caldb\&docid=62BA844B57E79D0483256EE5 006F5653

[9] Data utilized in the analyses presented here were obtained from microdata of these two surveys, taking into account the Brazilians 18 years old and over (the surveys were applied to Brazilians 10 years old and over).

[10] Information about internet access at home through dial up or broadband was obtained by means of two different variables. The two options are almost, but not totally, mutually exclusive.

[11] Minimum family income per capita. Per capita income is the sum of the revenues of all family members divided by the number of family members. Values in reais were $R \$ 300.00$ in 2005 and $R \$ 415.00$ in 2008.

[12] Minimum family income per capita. Per capita income is the sum of the revenues of all family members divided by the number of family members. Value in Brazilian Reais in 2008 was $\mathrm{R} \$ 415.00$. 